\title{
A Study to Assess the Knowledge Regarding Care of Unconscious Patients among Staff Nurses at NMCH, Nellore, Andhra Pradesh
}

\author{
P. Savithri ${ }^{1}$, Latha. $\mathrm{P}^{2}$, V. Jayanthi ${ }^{3}$, Dr. Indira Arumugam ${ }^{4}$ \\ ${ }^{1}$ Professor, Department of CHN, Narayana College of Nursing, Nellore, Andhra Pradesh, India \\ 2,3Professor, Department of OBG Nursing, Narayana College of Nursing, Nellore, Andhra Pradesh, India \\ ${ }^{4}$ Professor \& Principal, Department of MSN, Narayana college of Nursing. Nellore, Andhra Pradesh, India
}

\begin{abstract}
Background: Nursing the unconscious patient can be a challenging experience. Unconscious patients have no control over themselves or their environment and thus are highly dependent on the nurse. The skills required to care for unconscious patients are not specific to critical care and theatres as unconscious patients are nursed in a variety of clinical settings. Nursing such patients can be a source of anxiety for nurses. Aim: The aim of the study was to assess the level of knowledge regarding care of unconscious patients among staff nurses. Objectives: 1. To determine the level of knowledge regarding physical examination among staff nurses. 2 . To associate the level of knowledge with selected demographic variables. Methodology: 100 staff nurses working at Narayana Medical College Hospital were selected by using purposive sampling method. Results: Regarding the level of knowledge among staff nurses, 17 (17\%) had adequate knowledge, 76(76\%) had moderate knowledge and 7(7\%) had inadequate knowledge regarding care of unconscious patients.
\end{abstract}

Keywords : Knowledge, Care, Unconscious Patients, Staff Nurses.

\section{INTRODUCTION}

\section{"The first step towards knowledge is to know that we are ignorant"}

Nursing the unconscious patient can be a challenging experience. Unconscious patients have no control over themselves or their environment and thus are highly dependent on the nurse. The skills required to care for unconscious patients are not specific to critical care and theatres as unconscious patients are nursed in a variety of clinical settings. Nursing such patients can be a source of anxiety for nurses. However with a good knowledge base to initiate the assessment, planning and implementation of quality care, nursing patients who are unconscious can prove highly rewarding and the skills acquired can promote confidence in the care of all patients. ${ }^{1}$
The unconscious patient will require skilled emergency management. As a patient starts to become unconscious he or she loses control of his or her ability to maintain a safe environment. It cannot be stressed enough that the nurse has a crucial responsibility to anticipate, where possible, deterioration in a patient's condition (nursing and midwifery council (NMC) 2004). Thus in relation to consciousness, the nurse has an essential role in the assessment of the central nervous system using the GCS, monitoring vital signs, pupillary reaction and limb movements. Such skills will provide information that can allow for interventions to correct a life threatening deterioration and potentially avert a decline to unconsciousness. The A (airway), B (breathing), C (Circulation), D (Disability) approach 
to resuscitation should be adopted, and the maintenance of a clear airway is the first priority. ${ }^{2}$

Respiratory function, maintaining a patent airway and promoting adequate ventilation are nursing priorities. Assessment of the mouth and teeth is also important. Positioning the patient is important and will facilitate the drainage of secretions. The supine position compromises the mechanics of breathing and lung volumes (Hickey 2003). The accumulation of secretions over time can contribute to the development of atelectasis and hypostatic pneumonia. To maintain a patent airway the lateral recumbent position is advised (Allan 2002) with the head of the bed slightly tilted upwards, about 10-30 degrees. ${ }^{3}$

Pulse oximetry will aid the ongoing monitoring of respiratory function. Oxygen saturation is a measure of the percentage of hemoglobin molecules that combine with oxygen. Pulse oximetry assists in monitoring the effectiveness of oxygen therapy. Cardiovascular function - Monitoring the cardiovascular function in unconscious patients is of high importance. Alteration in blood pressure need to be viewed in relation to pulse rate, pulse quality and pulse pressure. ${ }^{4}$

The risk of venous thromboembolism and pulmonary emboli from the effects of immobility is well organized .The use of ant embolic stockings should be considered once the risk of venous thromboembolism has been identified. Nutrition and hydration is a fundamental need and yet evidence suggests that up to $40 \%$ of hospital patients remain malnourished. Therefore regular blood and urine tests to monitor electrolyte and metabolic changes are essential to promote accurate assessment of each individual patient. Nasogastric feeding is the most commonly used method and is recommended for short term feeding. Immobility also alters glucose insulin intolerance. An IV insulin sliding scale regimen may be required to maintain blood glucose levels within the normal range of $4-7 \mathrm{mmol} / 1 .{ }^{5}$

Hygiene needs and skin care - Attending to the hygienic needs of the unconscious patient should never become ritualistic, and despite the patient's perceived lack of awareness, dignity should not be compromised. Personal hygiene is considered part of the essence of care and needs to be carried out to a un compromising standard. ${ }^{6}$

\section{NEED FOR THE STUDY}

The World Health Organization (WHO) estimates that 5 million death occurs every year in Intensive Care Units. ${ }^{7}$

In India every year approximately 3.2 million ICU's admissions are occurring. In which $80 \%$ patients are in coma stage and in that 48000 deaths are occurring. ${ }^{8}$

In South India the overall ICU's admission in 2014 was $56.6 \%$ but Zimbabwe and Iran the admission was $20 \% 19.6 \%$ respectively. The overall causes in world about 20 million peoples are admitting in ICU's by various causes. ${ }^{9}$

A longitudinal study was conducted on unconscious patients in neurological intensive care unit (NICU) at sub-Saharan Africa. The aim of the study was to determine morbidity-mortality and survival of unconscious patients in NICU. It was a prospective longitudinal study for a period of 15 months. The study included over all $169(\mathrm{n}=169)$ patients. The mean age of the patient was $58.04+/-17.55$ years with a sex ratio of 0.92 . The mean time from installation of disorders and initial consultation was (8.88\%). The mean duration of hospitalization was $8.89+/-9.53$ days associated with mortality rate of $82.25 \%$ for a same period. Survival at day 90 was $10.65 \%$. Mortality was 
related to infection condition (28.4\%) renal failure (14.78\%) cardiovascular failure (13.16\%). Cerebral engagement (12.43\%), multiorgan failure (11.24\%), pulmonary embolism $(1.18 \%)$ and unknown cases (18.34\%). The study concluded that unconsciousness is associated with a high mortality rate in our context and suggests that early consultation, a good control of vascular risk factors and better management of infectious condition could reduce this impact. ${ }^{10}$

\section{PROBLEM STATEMENT:}

A study to assess the knowledge regarding care of unconscious patients among staff nurses at $\mathrm{NMCH}$, Nellore.

\section{OBJECTIVES:}

- To assess the knowledge of staff nurses regarding care of unconscious patients.

- To find out association between knowledge of staff nurses regarding care of unconscious patients with their selected socio demographic variables.

\section{DELIMITATIONS:}

The study is limited to;

- Who are working in NMCH, Nellore.

- Working in ICU, emergency and selected medical wards.

- Who are willing to participate

\section{METHODS AND MATERIAL}

\section{Research Approach:}

A quantitative approach was adopted to determine the research study.

\section{Research Design:}

The present study was conducted by using descriptive research design.

Setting:
Setting of the study was conducted at ICU, Emergency, and selected medical wards of NMCH, Nellore.

\section{Population:}

Target population: All staff nurses.

\section{Accessible population:}

Staff nurses working at ICU, Emergency, and selected medical wards of NMCH, Nellore.

\section{Sample:}

Staff nurses working at NMCH, Nellore and who fulfilled the inclusion criteria.

\section{Sampling Technique}

Non-probability purposive sampling technique was adopted to the selected samples.

\section{Sample Size:}

The sample size selected for the present study includes 100 staff nurses.

\section{Criteria for Sample Collection:}

\section{Inclusion Criteria}

The staff nurses who are:

- Willing to participate in the study.

- Available during the period of data collection.

- Staff nurses who are working in $\mathrm{NMCH}$, Nellore.

\section{Exclusion Criteria:}

- Nurses who are not available at the time of data collection.

- Nurses with managerial responsibilities like floor supervisor, nursing superintendent etc.

- Those who are not willing to participate in the study.

Variables of the study:

Independent variable: Staff nurses.

Dependent variable: Level of knowledge.

Description of the tool: 
Part-A: Demographic data consisting of items namely age, sex, qualification, experience, department where working, religion and designation.
Part-B: Self structured questionnaire to assess the knowledge care of unconscious patients among staff nurses.

\section{DATA ANALYSIS AND DISCUSSION}

Table-1 : Frequency and percentage distribution of level of knowledge among staff nurses. $(\mathrm{N}=100)$

\begin{tabular}{|l|c|c|}
\hline Level of Knowledge & Frequency (F) & Percentage (\%) \\
\hline Adequate knowledge & 17 & 17 \\
\hline Moderate knowledge & 76 & 76 \\
\hline Inadequate knowledge & 7 & 7 \\
\hline
\end{tabular}

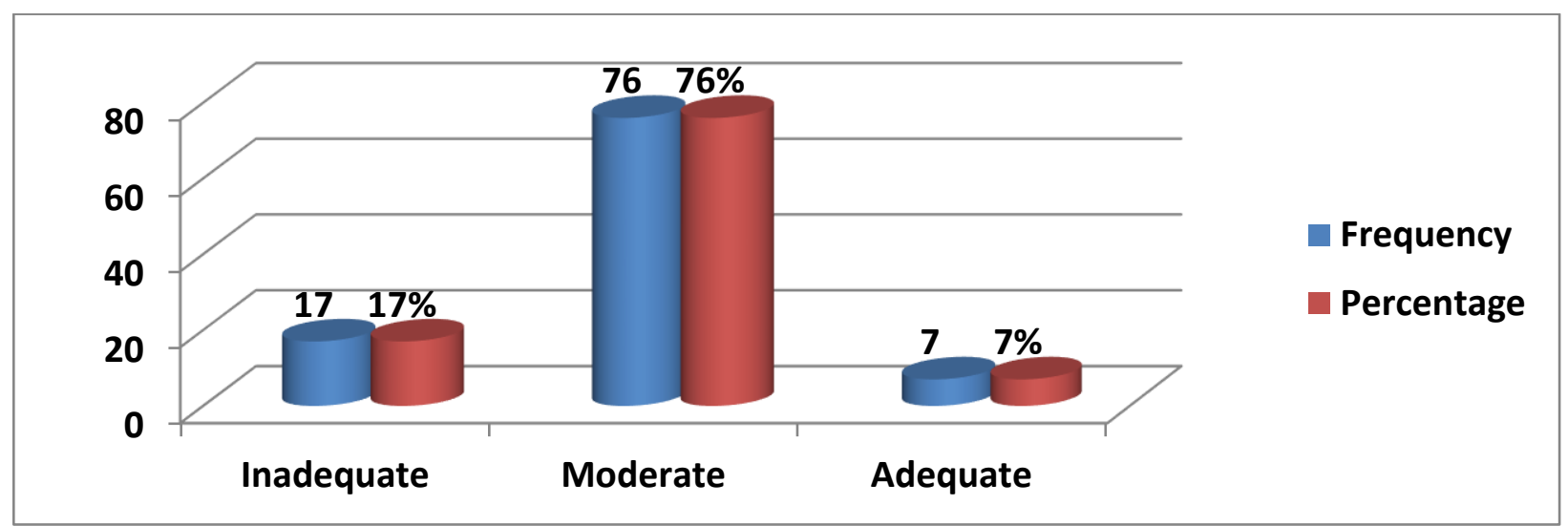

Fig 1 : Frequency and percentage distribution based on level of knowledge among staff nurses.

Table 2 : Frequency and percentage distribution of Mean and Standard deviation of knowledge. (N=100)

\begin{tabular}{|l|c|c|}
\hline CATEGORY & MEAN & S.D \\
\hline Level of knowledge & 20.85 & 6.87 \\
\hline
\end{tabular}

Table 3 : Association between level of knowledge and socio demographic variables among staff nurses. ( $\mathrm{N}=100)$

\begin{tabular}{|l|l|c|c|c|c|c|c|l|}
\hline S. No & $\begin{array}{l}\text { Demographic } \\
\text { Variables }\end{array}$ & \multicolumn{2}{|c|}{$\begin{array}{c}\text { Adequate } \\
\text { knowledge }\end{array}$} & \multicolumn{2}{|c|}{$\begin{array}{c}\text { Moderate } \\
\text { knowledge }\end{array}$} & \multicolumn{2}{|c|}{$\begin{array}{l}\text { Inadequate } \\
\text { knowledge }\end{array}$} & Chi Square \\
\hline & & F & $\%$ & F & $\%$ & F & $\%$ & \\
\cline { 1 - 5 } 1. & Age in years & & & & & & & $\mathrm{C}=13.413$ \\
& a. 15-20 years & 13 & 13 & - & - & - & - & $\mathrm{T}=11.76$ \\
& b. 20-25 years & 10 & 10 & 76 & 76 & 1 & 1 & $\begin{array}{l}\mathrm{Df}=6 \\
\mathrm{P}<0.05 \\
\end{array}$ \\
& & & & & & & & \\
\hline
\end{tabular}




\begin{tabular}{|l|l|c|c|c|c|c|c|l|}
\hline 2. & Educational & & & & & & & $\mathrm{C}=18.654$ \\
& Status & 11 & 11 & - & - & 1 & 1 & $\mathrm{~T}=17.97$ \\
& 5 & 5 & 76 & 76 & 7 & 7 & $\mathrm{Df}=4$ \\
& a. GNM & & & & & $\mathrm{P}<0.05$ \\
& & & & \\
\hline 3. B.Sc.Nursing & & & & & & & $\mathrm{C}=22.701$ \\
& Area of Work & & & & & & & $\mathrm{T}=19.11$ \\
& a. ICU & 12 & 12 & 15 & 15 & - & - & $\mathrm{Df}=3$ \\
& b. Emergency & 2 & 2 & 43 & 43 & 5 & 5 & $\mathrm{P}<0.05$ \\
& c. OT & - & - & 9 & 9 & 1 & 1 & \\
& d. Ward & 2 & 2 & 9 & 9 & 1 & 1 & \\
& & & & & & & \\
\hline
\end{tabular}

\section{MAJOR FINDINGS OF THE STUDY}

Regarding the level of knowledge among staff nurses, 17 (17\%) had adequate knowledge, 76(76\%) had moderate knowledge and 7(7\%) had inadequate knowledge regarding care of unconscious patients.

$\checkmark \quad$ The mean knowledge score of staff nurses was 20.85 and standard deviation was 6.87.

$\checkmark$ There was a significant association found between level of knowledge and demographic variables such as age and working area at $\mathrm{P}<0.05$ level.

\section{CONCLUSION}

Hence it can be concluded that most of the staff nurses had average knowledge (76\%) towards care of unconscious patients. Hence there is an immense need to implement an educational programme for all nursing students about care of unconscious patients.

\section{REFERENCES}

[1]. Carol Jaylor, "Text book of fundamentals of nursing", 4th edition, published by Lippincol, Page no.84-86.
[2]. Latha.P, A study to assess the knowledge regarding discharge procedure among staff nurses and nursing students in NMCH, Nellore, Narayana Nursing Journal, 2017, 6(3), 10-13.

[3]. Joyc $\mathrm{T}$ M.Blake, “Text book of medical and surgical nursing", 6th edition, published by Harcourt, Page no.110-115.

[4]. Riya Mathew, P Latha, N.Subhashini, Dr. Indira Arumugam A study to assess the knowledge regarding INC norms for b.sc nursing programme among nursing students in Narayana college of nursing, Nellore, International Journal of Academic Research and Development, 2017, 2(4), 655-656.

[5]. P.Latha, Anju mol, Level of Knowledge regarding IPR among staff nurses and students at NMCH, Nellore, 2016, 5(3), 19-21.

[6]. Arundathi S, Latha P, Dr. Indira Arumugam A study to assess the knowledge on factors affecting nursing practices among nursing staffs in NMCH at Nellore, International Journal of Advance Research in Nursing, 2019; 2(1), 1720.

[7]. P.Latha, Anjaly Joseph, Dr.S.Indira Knowledge regarding recording \& reporting among staff nurses and nursing students at NMCH, Nellore, International Journal of Applied Research, 2016, 2(11), 436-438. 
[8]. J Samhitha, Latha P, Dr. Indira Arumugam, A study to assess the knowledge on objective structured practical examination (OSPE) among B.sc Nursing students at selected college, Nellore, International Journal of Midwifery and Nursing Practice, 2018; 1(1), 16-18.

[9]. Lippincott (2000) "Manual of nursing practice;" 8th edition; Jaypee publication; New Delhi; p945-p954.

[10]. Tincy Thomas, P. Latha, Dr. Indira S, B. Kavitha, Knowledge regarding INC norms for post basic B.Sc nursing programe among faculty in Sree Narayana Nursing, Nellore, Andhra Pradesh, International Journal of Academic Research and Development, 2017, 2(4), 338340 .

\section{Cite this article as :}

P. Savithri, Latha. P, V. Jayanthi, Dr. Indira Arumugam, "A Study to Assess the Knowledge Regarding Care of Unconscious Patients among Staff Nurses at NMCH, Nellore, Andhra Pradesh", International Journal of Scientific Research in Science and Technology (IJSRST), Online ISSN : 2395-602X, Print ISSN : 2395-6011, Volume 6 Issue 2, pp. 732-737, March-April 2019. Available at doi : https://doi.org/10.32628/IJSRST1962122 Journal URL : http://ijsrst.com/IJSRST1962122 